This is an electronic version of an article published in Gallagher, K., \& Lortie, P. (2005). 'How does knowin' my business make you any safer?: Critical pedagogy in dangerous times. The Review of Education, Pedagogy, and Cultural Studies, 27(2), 141-158. Cognition and Instruction is available online at: www.tandfonline.com with http://www.tandfonline.com/openurl?genre=article\&issn=1071$4413 \&$ volume $=27 \&$ issue $=2 \&$ spage $=141$

\title{
'How does knowin' my business make you any safer?': critical pedagogy in dangerous times
}

\author{
Dr. Kathleen Gallagher and Mr. Philip Lortie
}




\title{
'How does knowin' my business make you any safer?': critical pedagogy in dangerous times
}

\author{
Dr. Kathleen Gallagher and Mr. Philip Lortie
}

\author{
Submitted to The Review of Education, Pedagogy, and Cultural Studies \\ September 10, 2004
}

This paper has not been previously published nor has it been submitted for review to any other journal.

Kathleen Gallagher is Associate Professor and Canada Research Chair in Urban School Research in Pedagogy and Policy in the Department of Curriculum, Teaching and Learning at the Ontario Institute for Studies in Education of the University of Toronto (OISE/UT). Dr. Gallagher's book Drama Education in the Lives of Girls: Imagining Possibilities (University of Toronto Press, 2000) received the American Education Research Association's book award for significant contribution to Curriculum Studies in 2001. Her recent edited collection (ed. K. Gallagher and D. Booth) is entitled How Theatre Educates: Convergences and Counterpoints with Artists, Scholars, and Advocates (University of Toronto Press, 2003). Dr. Gallagher's research in drama continues to focus on questions of inclusion and democratic practice as well as the pedagogical possibilities of learning through the arts.

Philip Lortie is an M.A. student in the Department of Curriculum, Teaching and Learning at OISE/UT. His proposed thesis is titled A ssumed Identity: a case study in drama and masculinity. In addition to working as a Research Assistant with Dr. Gallagher, Mr. Lortie currently teaches Drama in the Initial Teacher Education program at OISE/UT.

Kathleen Gallagher, Ph.D.

Associate Professor

Canada Research Chair

Ontario Institute for Studies in Education of the University of Toronto

Department of Curriculum, Teaching and Learning

252 Bloor Street West

Toronto, Ontario M5S 1V6

Telephone: 416 923-6641 ext. 2015

Fax: 416 926-4744

Email: kgallagher@oise.utoronto.ca

Mr. Philip Lortie

M.A. Candidate/Adjunct Instructor

Ontario Institute for Studies in Education of the University of Toronto

Department of Curriculum, Teaching and Learning

252 Bloor Street West

Toronto, Ontario M5S 1V6

Telephone: 416 923-6641 ext. 7859

Email: plortie@oise.utoronto.ca 


\begin{abstract}
The paper is an account of the second year of a three-year research project titled, Drama Education, Youth, and Social Cohesion: (re)constructing identities in urban contexts, examining the experiences of youth in urban drama classrooms, and the dynamic forces of inclusion and exclusion experienced there. The researchers contemplate findings based on a methodological shift, in which they dramatically engage the students in an exploration of their pressing concerns about the school administration's new security policies. The students' issues provide clear examples of just how far the neoliberal agenda in schools has gone and the unambiguous ways in which democracy is under attack. Implications of this experimentation are drawn for educators and researchers about the potential of attuning to students' 'watching' as a developing pedagogy, a form of critical engagement of the imagination, and a space for creative resistance against the school's institutional gaze.
\end{abstract}




\section{'How does knowin' my business make you any safer?': critical pedagogy in dangerous times}

\section{Public Imagination as Occupied Space}

As we write, the New York State's Department of Education website homepage offers a scrolling message, highlighted in yellow, that reads: "New York State is now at a Yellow

Alert Level (Elevated). All New York State schools outside New York City should follow the guidance for Yellow Alert Level (Elevated) in the NYS Homeland Security System for Schools. New York City remains at an Orange Alert Level (High). Guidance on that level is also contained in the Homeland Security Document". When I click on the "Color Coded Risk Level System and Recommended Actions for Schools Flowchart”, I learn that level Blue (Guarded), beneath both levels Yellow and Orange, already calls for increased security. So we are somewhere in between being "Normal" (Green) where we are told to "continue normal operations" and "Severe" (Red) where we "close down the school, follow lockdown procedures, and transfer to an emergency shelter". But clearly, nothing is "normal" in schools anymore. "Risk", and its now familiar bedfellow "suspension of civil liberties" is ever present. Such is the largely unquestioned new school face of the neoliberal order.

Within this neoliberal order, David Livingstone, at a recent lecture ${ }^{1}$ outlined three kinds of contemporary capitalism: Shareholder Capitalism, Stakeholder Capitalism, and Democratizing Capitalism, with the latter being both the only sustainable economic system and the one in which the breaking down of hierarchized and ritualized workplace behaviours could be accomplished. This, he claimed, means combining learning with everyday life in order to create the conditions for greater participation of workers and use of their skills within our context of an "increasingly 
willfully ignorant society". I draw on this analysis of neoliberalsim and labour to make the analogy that a democratizing pedagogy, much like a democratizing capitalism, needs to create spaces in which students might disturb the new everyday rituals of public school through which they are commonly positioned as potentially dangerous outsiders- the anti-citizens- in the new world order. Peter McLaren (1986), in his influential study of an inner-city, Canadian classroom, claimed that drama was one method by which educators could de-stabilize the givens and take the lives and experiences of their students seriously:

Drama is the ritualizing of imagination, and my imagination, unlike my body, is not sitting under a tree taking notes. If my body is ever to unlearn its boredom and find its ritual rhythm, it will do so dramatically. It will do so by pretending and imagining (239). But both McLaren's and Livingstone's democratizing agendas need to be understood within the context of what Strictland (2002) has described as one of the most harmful neoliberal social and economic policies in the U.S. (and elsewhere); namely, that the “...corporate sector demand for a curriculum of narrowly defined skills training in public schools and universities [is] undermining public education's role as a democratic social institution" (p.2). The social cost of leaving young people out of the equation and unable to access forms and forums of democratic participation in and beyond their classrooms is immense. This article will attempt to understand some of the ways in which youth subjectivities are constituted in the neoliberal order, the ways in which their behaviours are ciminalized, and the harrowing manner in which school, as one site, is complicit in a larger cultural disinvestment in youth.

We accomplish this through an analysis of a drama activity with youth that aimed to "hold a mirror" up to the various policing measures inflicted upon a fictional group of workers

\footnotetext{
${ }^{1}$ The annual Jackson Lecture was held at the Ontario Institute for Studies in Education of the University of Toronto on October $14^{\text {th }}, 2004$. Dr. David Livingstone's lecture was titled, The Learning Society: Past, Present and Future
} 
(the youth in role) in order to see how this kind of theatre pedagogy and analogous thinking might explore our sense of the imagination as occupied space in the current criminalizing of youth in schools. Playwright Brian Friel says that we, in the arts, talk “...glibly and unwittingly of holding the mirror up to nature because we don't really know what that means; that we think theatre should be a flattering reflection of the life we lead or think we lead (p. 15). In contrast to this, we took seriously Deborah Britzman's (2001) question- "How is art different from life and how is art too close to life?"- (p.25) in our pedagogical experimentation and examination of a social, political, and economic order that is not only an unflattering reflection of life but an unconscionable one. Wilshire (1982) is correct when he claims that any attempt to understand theatre as an isolated craft is bootless. To study theatre, he claims, "is to find oneself in the vast sweep of human activities that circle back upon themselves. Through the proxy of theatre's drama we discover actual and possible "dramas" of everyday life in which we are tested and confirmed, both individually and collectively" (p. 240).

Freire (1998) has many times claimed that ethics and aesthetics are intimately tied together. Of the neoliberal ideology, he has also written:

It is necessary to unmask the ideology of a certain neoliberal discourse, called at times the "modernizing discourse", that, speaking about the present moment in history, tries to convince us that life is just like this: The most capable organize the world, they produce; the least capable, survive" (p.58).

And so a methodological experimentation invested in using theatre, the theatre of analogy and metaphor, to "unmask" the experiences of youth in the security-obsessed culture of schools in North America seemed right. This theatre work did allow us to make problematic the forces youth describe as constructing their identities in negative ways and limiting their capacity to 
fully participate in public life. What we attempt to do in the last section of the paper is come to grips with the more difficult pedagogical question of what it means to go beyond simply "unmasking" the issues and, further, how a democratizing pedagogy might usher in such a project.

\section{Theatre Pedagogy as Methodology}

Within the various discourses of pedagogical theory, the comparison between teaching and acting is often made (see Showalter 2003; Eagleton 1996; Felman 2001; Martusewicz, R. 2001; Eble 1988 to name but a few). Actors, it might be said, make for good teachers, owing to their ability to "make it up as they go along". Equally, actors might make poor teachers if they fail to take the audience in, fail to communicate clearly and read their audience well. In this paper, we would like to make just such a comparison between "acting" and- this time- "researching", especially when the lines between researching and teaching become obviously blurred, where research becomes both a scientific and a pedagogical inquiry. Our methodological experiment, invited us, as researchers, to respond pedagogically and theatrically to the fervent concerns of youth research participants in an attempt to co-construct knowledge differently. Freire (1998) again was useful as we struggled to consider the kind of relationship between educatorresearchers and learners we sought:

I believe that the basic question that we educators, quite lucid and ever more competent, should confront is that our relationship with the learners is one of the roads that we can take to intervene in reality over both the short and the long term. In this sense (and not only in this sense but in others as well), our relationship with learners demands that we respect them and demands equally that we be aware of the concrete conditions of their 
world, the conditions that shape them. To try to know the reality that our students live is a task that the educational practice imposes on us: Without this, we have no access to the way they think, so only with great difficulty can we perceive what and how they know (p.58).

The larger empirical study within which this story is situated aims to examine the experiences of youth in urban drama classrooms in order to develop a theoretical and empirically grounded account of the dynamic social forces of inclusion and exclusion experienced by adolescents within their unique contexts of public, urban North American schooling. Drama Education, Youth, and Social Cohesion: (re-) constructing identities in urban contexts ${ }^{2}$ is an ethnography of four urban sites- two in Toronto, two in New York City- particularly concerned with investigating the extent to which drama education in classrooms illuminates the intersections of youth's personal/cultural lives with their school lives in the formation of their social, academic, and artistic identities. What we refer to as the second phase of our research had us bringing "raw data" (individual interview transcripts, student writing, focus group conversations) from the previous year's fieldwork with one classroom of drama students (grade 11, 16-17 years of age) into a new drama classroom (grade 12, 17-19 years of age) at one of our school sites in Toronto. Our intention was to have these new students work with the data in order to help us check our own provisional understandings and to re-direct our eye toward areas of significance for the youth that had eluded us. The approach, however, did not garner anywhere near the enthusiasm and interest we had hoped for. Their lack of engagement stood in sharp contrast to a passionate discussion that erupted in the classroom on our first day of observation about the students' growing concerns regarding their sense of perpetual surveillance and anti-

\footnotetext{
${ }^{2}$ We gratefully acknowledge the Social Sciences and Humanities Research Council of Canada for their support of this research.
} 
democratic school policies and procedures. These new policies, they felt, were appreciably altering their experiences of school and their conceptions of subjectivity. While Chomsky (2000) may be right when he says that schools are institutions for indoctrination and for imposing obedience, there are times when the oppositional voices of youth break through in stunning ways.

We asked ourselves what we might do as researchers (and teachers), therefore, when such cogent voices challenge the control and coercion so pervasive in schools today. And this is when we took the decision to act on our firm belief that knowledge created through improvised dialogue, and through dramatic improvisation especially, is knowledge of a different sort, accessed and processed differently than most other things in the regular high school classroom. Our methodological approach shifted sharply, when we fell upon the idea that we should dramatically engage the students in an exploration of their pressing concerns by creating an analogous environment that might ignite just such an improvised dialogue. Researchers cum teachers cum actors, we created a "fictional" world of surveillance and discrimination, a metacontext in which to spontaneously engage the students in their seemingly serious concerns about a new surveillance system of technologies in public (school) space ${ }^{3}$ closing in upon them.

\footnotetext{
${ }^{3}$ For a further discussion of these ideas, see Gallagher and Fusco's (2004 forthcoming) paper, I.D.ology and the Technologies of Public (School) Space: Who Are The Terrorists Among Us, which explores spatial and architectural theory in a Foucauldian analysis of space, power, and the subject, as a frame within which to examine moves toward security in Canadian urban schools. Policies and technologies of record-keeping, identification-verifying, and spatial arrangements are producing altered experiences of subjectivity and the ways in which youth, workers, and researchers experience public (school) space. The paper argues that notions of 'risk' and 'otherness' in the nation state, and the exploitation of real fears in the wake of real school violence, have permitted a culture of acute surveillance.
} 


\section{Watching As Critical Pedagogy}

As we hope becomes clear in the following description and analysis of a process drama ${ }^{4}$ we led, we believe the extent to which dramatic work acknowledges - indeed, subsists on - the productive capacity of the act of watching uniquely qualifies it as a site to disrupt the regimenting and polarizing of student identities that has arisen from an increasingly paranoid security apparatus within urban public schools. This brave new world of the school is aptly described by Lewis (2003) as the "digital gaze of disciplinary power" (p.340). He argues further that "...teachers are adopting a new form of surveillance pedagogy as the only viable response to the threat of school violence" (p. 345). Predictably, the terms of the debate about school safety in a post-9/11 world reflect our collective preoccupation with terror, security threats, and the susceptibility of democracy to infiltration and overthrow. And, in further correspondence with broader social trends, schools now employ stricter surveillance in the form of information gathering and constraint of access to, and within, the school. In such an institutional setting, Drama seems a kind of oasis, in which students can come together to think and act spontaneously, to command a space, to watch each other outside of the institutional gaze, to challenge stereotypical notions of identity and motive, and to think strategically about how to survive in an era of heightened distrust of difference. Our unexpected methodological experiment has compelled us therefore, as researchers and teachers, to reclaim the gaze, to enliven the act of watching for its pedagogical potency.

Not only are students' movements and behaviors in the hallways and public areas heavily regulated through top-down security initiatives, but the typical classroom re-enforces the call for

\footnotetext{
4 "Process drama" is a general term used to describe a method of drama instruction in which, typically, the teacher and the whole class enter into an imaginary context, often based on source material gathered by the teacher or students. The goal is to investigate any of a number of possible themes through sustained improvisation, during which students and teacher might take on a variety of roles and relationships through various theatrical conventions.
} 
obedient conformity by equating stillness with seriousness, or quiet with acquiescence, and through its mechanistic turning of the students' attention from task to task. In the multifaceted action of an improvisation, by contrast, participants are freer to direct or pay attention to what they want. Each participant's watching mediates the extended group improvisation, because what I see influences how I respond, which in turn informs what others will see and how they respond. As a result, a clearing is created for an inquiry into the social construction of identity, all in the guise of asking students to reflect - in or out of role - on the relationship between actor and role, action and participants, and finally, between what they saw and what they did.

Ask students of Drama what makes the class enjoyable and you inevitably hear that Drama's fun because you "get to do stuff," and because you don't have to sit in pre-assigned seats, face front and mind your own business. Drama classrooms are often more casual spaces in which students may organize themselves physically within an open area. As several students emphasized, they come to Drama ready for anything, expecting to be up on their feet, moving, acting, pretending. After hearing this refrain numerous times, however, another theme emerges. Within the less regulated space and time of a Drama class, the excitement is not only about a relaxation of the rules and playing fun games, it is also strikingly about community, collaboration, and identity. Among the students we interviewed, a commonly perceived benefit of Drama is "getting to know students you never did in other classes you took together" and "in ways you never would in other classes". The students frequently report that they feel the connections they make with other students in Drama are stronger, sometimes precisely because they are formed outside of their everyday social networks. In a conversation with Anna Deveare Smith, Lani Guinier, concludes that theatre is often a sanctuary. Like the students, she says, "It can be a place where people connect in ways that are otherwise improbable or impossible". Later 
in the same conversation, Guinier insists that the theatre is, in some ways, “...our last hope for creating or at least reviving our democracy, because without those opportunities for this multidimensional kind of public engagement and interaction, people simply retreat into the private sphere of entertainment and spectacle" (2002, p. 39). Fundamental to how Drama builds its community, we will suggest, is how, in particular, it taps the rich creative potential in the act of watching. In other words, Drama is fun because it subverts the scholastic regimentation of students' attention to proscribed artifacts for defined periods of time by troubling the notion that watching and doing (not to mention thinking) are distinct activities, and that everything they need to know can be found in their assigned reading of things.

\section{Watching in Drama Class}

A Drama student begins her creative collaboration mid-performance, with a roomful of others also cast in the multiple social roles of student, classmate, and teenager. Any move they make into the imaginative realm may interrupt routine classroom dynamics, but the meta-theatrics of the students' social positioning remain in effect, so that choices of setting, character, and action are continually interpreted by participants and driven by the needs of the drama's pretext as well as external (social) concerns. The duality of "fictional" and "real" in drama makes it unique among school subjects. When working in an imagined context, every word, every gesture and every glance can be viewed as a contrivance, and such complicit dissembling can unsettle the ground upon which students stake their "real" personas outside of role. The actual stage operating within the metaphoric stage of the classroom means there are no neutral spaces, where even the passive role of spectator becomes implicated in the construction of an alternate world. As students shift into role-play, they are aware (to varying degrees) of their position in the class 
both relative to their peers/teacher and to the role they are inhabiting; the device of becoming somebody else for even a brief while introduces a range of choices perhaps otherwise unavailable to these students.

This is why, as researchers, we constantly remind ourselves that in order to capture the movement and character of what we are seeing we need to ask "who is doing what differently?" As it turns out, the question furthered our thinking about Drama in general, as it prompted us to imagine the ways in which we could help students to ask this question, thereby opening up the ways in which students watch each other, and watch themselves watching. This also made tangible for us Giroux' (2003) notion of pedagogy as a mode of witnessing. Effectively, it became a way of critiquing as Foucault (1990) describes it, “... a matter of pointing out on what kinds of assumptions, what kinds of familiar, unchallenged, unconsidered modes of thought the practices that we accept rest" (p.154).

In the heat of the discussion about the school's latest policing activities - the very conversation that prompted us to better "read" our audience in one Toronto school and shift gears both pedagogically and methodologically - a black female student, Adeline, declares that she no longer feels comfortable at the school, so much so that she finds it harder to concentrate in her classes; she believes the school is too regimented - "it feels like we're a bunch of robots." A bit later, Lee, a black male student, in offering some cool-headed advice, inadvertently echoes Adeline's observation: "You just have to be smart and listen and study. Do everything they say even if you don't agree. Just do it and you can get out." Never mind the pause this gives us as researchers as we wonder to what extent Lee's participation in our study follows from this "goalong-to-get-along" credo. How can we, in our practice as educators and critics, counteract, or, minimally, trouble the schools' mandate that students assent to whatever the institution requires 
of them for security purposes? Presumably it is still within our power to cast doubt on the efficacy of this approach, with its inherently biased notions of who, or what, constitutes a threat. To ignore this challenge would be to abandon our commitment to transformative or liberatory practice, and educational research for social justice ${ }^{5}$.

\section{Employees' Performance Review: a process drama}

As critical educators we must resist the anti-democratic impulse now dominant in our public institutions by, as Leistyna (2003) urges, abandoning liberal notions of education as empowerment in favor of promoting an open-ended dialogue that originates with students' experiences and theories about their world. Rather than looking for pat answers to irrelevant questions, educators committed to social justice take seriously the potential of creative problemsolving in transforming the felt and lived conditions of students' lives. Therefore, we believe that by creating believable fictions based on students' experiences, and exploring dramatically how power operates through them, we are honing our students' ability to identify the myriad contradictions that exist between their experience of schooling and its purported aims.

In the present case, the fictional world we entered into with these students was based upon concerns they expressed about surveillance within schools. Using the alternate dramatic framework of a six month probationary review at an unspecified company, we hoped to recreate the dynamics of a monolithic security apparatus, specifically the ad hoc bureaucratic variety in which the inadequacies of the system encourage even those with nothing to hide to engage in deceit, merely to avoid even greater inconvenience. Dr. Gallagher and Mr. Lortie, now in their respective roles as security screener and interviewer, barked out instructions for the "employees"

\footnotetext{
${ }^{5}$ See Morwena Griffiths (1998) text, Educational Research for Social Justice: getting off the fence for a developed thesis on productively biased research for social justice.
} 
to line up and be prepared to show identification when asked. Students were then arbitrarily called forward, ${ }^{6}$ put through a frustrating sequence of security checks, in which some had their identification seized, or were told to wait indefinitely. Those who made it through to the interview were asked to verify the date of their arrival to Canada, to explain their association with difficult employees, or to defend their lack of conformity to the corporate rules of conduct. With an almost disquieting ease, the students embodied lowly employees fighting for - if not justice - a fair shake from a pair of administrators more interested in regimentation than efficacy.

By the end of the thirty minutes of in-role work, the room was buzzing with employees upset with the treatment they received, talking amongst themselves and demanding follow-up interviews. When the group was informed that it was time for the bureaucrats' lunch break, a great howling and shrieking ensued, with the employees outraged that they would have to wait there for an hour or more. We strode out the door, thereby ending the extended improvisation. Upon returning, we informed the students that many of them were fired, and that they should now write a letter to the Director of Personnel to complain.

Below are excerpts from letters written by three students in role as employees:

\section{LETTER \#1}

Your store is the epitome of an evil corporation, you couldn't pay me enough to come back and look at my big ugly supervisors. Anyways thank you for your time.

\section{EAT SHIT.}

Employee \#5479.

You probably wouldn't know my name if you saw it.

\footnotetext{
${ }^{6}$ Though chosen apparently at random, those brought forward were mostly the quieter students for whom Dr. Gallagher wanted to provide a performance opportunity. This is an example of how teachers working within
} 
A playful response, but nonetheless effective in depicting the depersonalizing aspect of these types of encounters.

The following two letters provide clear examples of students basing their responses on what they witnessed within the improvised action.

\section{LETTER \#2}

I don't know what you trying to run here. What ever it was didn't work. I saw only 3 people get hired. 3. What the hell out of all those people there if you do nothing about it then I will go to higher authority.

\section{LETTER \#3}

I would like to address the employee review which took place several weeks ago, as I have some concerns with the events that occurred. Employees were rounded up and taken to an interview, during which we were fingerprinted without consent. Every employee that was brought to the interview was not paid for the time we spent there. Many employees had identification that was seized.

Both of these letter writers, with no prompting from their teacher or us, chose to refer to events outside of their direct experience in communicating their dissatisfaction to the Director of Personnel. Seamlessly woven into their account, the details they provide buttress their complaints about the ineffectiveness of the probationary review process and lend authenticity to their view of the fictive events. Such extension of the dramatic moment underscores claims regarding the rich potential of role-play in the classroom, but, more importantly, clouds simplistic distinctions between active and passive, doing and watching, being and seeing. 


\section{Some Observations to Consider}

The rituals of schools and curricula in a neoliberal context and the pedagogical imperatives of corporate-driven, standards-obsessed classrooms create formidable roadblocks for those teachers and students who might wish to link their understanding, their critical imaginations, with larger projects of social engagement or activism. From the experience we have described here, we are left wondering how to begin to connect a student's deep engagement in a theatre moment with political and intellectual activism. Our first instincts tell us the following:

1) We must find ways to open up the occupied space of the imagination, locked in place by Freire's notion of the "modernizing discourse" that tries to persuade us that things are just this way. The critical imagination, instead, asks students to make something of their watching, to add their critique into the action as it unfolds, and to be responsive to and make something of their witnessing of others.

2) Like Deveare Smith and Guinier (2002), we think that the "aha" moments of theatre, or any other kind of profound learning experience, cannot be the baseline by which one measures success. Especially given the intermittent school attendance of many young people, we know that pedagogical relationships take time and must, therefore, strongly resist the endsdriven curriculum of the day in order to build the kind of relationships in classrooms in which people might engage with each other and from which they may, at other times, productively withdraw to restore themselves and access their own creativity, as do the artists that Guinier describes. A democratizing pedagogy will create intentional communities outside the prevailing notion of school citizen as subject of curriculum hoop-jumping and consumer of curriculum-testing. 
3) Deveare Smith (2002) says: "To make social change, it takes more time than once, and it takes something that is even probably not very interesting" (p.38). The improvised moment of drama pedagogy draws most from the everyday-ness of the improvisers' lives. It is also full of missteps and recoveries. It is not a one-off, nor a rarified art experience, but a collective enterprise deeply connected to the quotidian in all its interest and tedium.

4) A democratizing pedagogy invites students to disrupt their habits of thinking by making public their readings of the story. It is only in the engagement between co-improvisers (students) that collective action can be imagined among disparate groups. Strickland (2002) has asked us to consider what is left of enlightenment values and institutions, what can be preserved and adapted to help young people resist new forms of exploitation characteristic of neoliberalism (p.13). After "holding the mirror up" to these new realities, through process drama or critical media studies for instance, students themselves must find viable modes of resistance to the assault on their imagination that the consumer greed of global capitalism inflicts.

5) Finally, the act of watching in the pedagogical moment, must be decoupled from prevailing ideas of passivity or inertia in education. Theatre operates in a world of watching and being watched, but even the most progressive classrooms still position watching as a static act. Making discoveries in a classroom based on attention paid to co-collaborators is a powerful way to learn. In turn, knowing that the operating pedagogy of a classroom will take account of each student's actions and observations builds the kind of relationships that move more strategically toward greater social engagement and potential collective action.

In a recent interview, Tony Kushner (2004) is asked how the art form of theatre helps us address the present. He replies that theatre and art have a number of values in "helping people 
get through life and teaching certain ways of looking at the world and of understanding the world, of reading the world critically in a complicated way, a dialectical way" (p. 40). Although, for Kushner, nothing substitutes for political activism:

And because we actually live in a working pluralist democracy and are citizens of a democratic republic, not disenfranchised yet, I think that we have a moral imperative to act and to organize (p.40-41).

We wonder, however, whether this is how many of the students we have met and recently worked with would describe their engagement with their world. The question remains: can theatre provoke the moral imperative where it is not?

\section{The Junction of Space and Subjectivity}

In his interesting study of performance, privacy and surveillance space, McGrath (2004) claims that the expression "You are under surveillance" is no longer an announcement made to a selected individual—it is a description of our culture:

You are under surveillance. Not many years ago, this statement could not have been made in a generalized form to an unknown addressee. Today, assuming that you are an urban dweller in a developed country, to be 'under surveillance' is a general condition ( $\mathrm{p}$. 19).

Today, assuming you are a high school student in an urban public school in North America, you can expect that most areas of the school will be monitored by video cameras, most washrooms will be under lock and key, most lockers will be closed permanently, and most teachers/guidance 
counselors/administrators will have access to your and your family's personal information regarding such things as health, immigration status, and education and employment history. ${ }^{7}$ We can not say whether drama pedagogy and the premium it places on productive forms of watching can counter, to any great extent, what Lewis refers to as the "new surveillance economy" in schools and in public life more generally. He writes:

A militarized state cripples democratic public life, and presents us with a forced choice between either perpetual danger or hyper-panopticism. Safety must be decoupled from neoconservative militarism and neoliberal commodification, and in the process, realigned with trust, compassion, and solidarity (p.353).

What we do know, however, is that our own research efforts were radically altered by the attention we chose to pay to the spontaneous and improvised dialogue that erupted among youth who felt they had a stake in something both "imagined" and "real". In catalyzing their watching and creating a context for interaction and play, we could no longer mistake their "reluctance" for apathy, menace, or social disorder. We had instead tapped into one of the most refined skills of adolescents- their critical assessment and healthy suspicion of their own world- in order to better understand their analysis of this new state of surveillance and security that has powerfully regulated their civil liberties within the school's walls.

Giroux (1998) has argued that the bodies of youth are sprawled across the media in a public display of social disorder, laziness, menace, and aberrant promiscuity. Youth, he continues, have been projected as a social problem second only to race-bound issues such as multiculturalism, welfare reform, and immigration:

\footnotetext{
${ }^{7}$ In addition, in one of our New York school sites, the students were subjected to random drills throughout the school day, in which the principal would announce an "Operation Clear Sweep" over the public address system and all students were required to vacate the hallways immediately or they would be taken down to the "Office of Discipline and Security" for reprimand.
} 
If a crisis of representation regarding youth has emerged in the 1990s, it is rooted less in a transformation of representational ideologies than in a host of complex national and global forces changing the face of the contemporary urban landscape: a downwardspiraling economy, a resurgent racism, a diminishing allocation of funds for crucial public services...These factors, among many others, appear to register a shift from media culture's simplistic but sometimes sympathetic portrayal of youth as a lens through which to analyze the social and political dynamics at work in the larger society to its current more racist and brutalizing view. Young people are no longer seen as a symptom of a wider social dilemma - they are the problem (p. 44).

Given the sedating effect of such ubiquitous images, pedagogy- and research on pedagogy- must find new ways to enact the potential of the postmodern, where, as Besley (2003) would have it, “...new gender roles, new identities, new cultural practices, new family configurations..." are already possible. And if, as Lesko (2001, p. 17) describes it, "the human being of posmodernism is understood as a text, as a composition, as a bricollage, or as a performance without an essential core", then the decidedly self-conscious inventiveness of drama pedagogy may have something to offer. If, in the improvised moment, we (the actors) watch others, watch ourselves being watched, watch ourselves watching (as researchers, teachers, youth), the multiple texts informing, both consciously and unconsciously, our imagined/real roles and actions might help us to recognize, analyze, and even resist such dominant and stereotypical images. At the very least, drama engagement can help to dismantle/assemble- piece, by interesting piece- the construction of a self, a culture, an institution and unequivocally reveal these subjects as served by/serving and/or countering dominant ideologies and political interests. 
In post-9/11 North America, safety and freedom are now held as opposing values. President Bush's rhetoric aside, freedom has no place in his administration's attempts to bring stability to the world, unless of course the Navy were to deploy a destroyer named U.S.S. Freedom, replete with Tomahawk ${ }^{\mathrm{TM}}$ precision strike cruise missiles. When President Bush utters a phrase such as "they hate our freedom," his language is meant to invoke in the mind of his audience such cherished notions as freedom from religious persecution, or censorship, but can only plausibly be referring to such things as energy industry representatives re-writing environmental regulations, tax-exempt off-shore holdings for the wealthy, and multinational corporations, such as ExxonMobil, gaining greater access to the Iraqi oil reserves.

Contrast this set of privileges and liberties with the trend in the public sphere. Americans (in and out of school) are fed a steady diet of warnings about their susceptibility to another terrorist attack. And what makes them so vulnerable? Their freedom, naturally. Again, not the freedom of U.S. interests to act with economic and military impunity around the globe, but the conspicuously abundant freedom of ordinary citizens to walk the streets, check out books from a library, make phone calls, travel across borders, mail letters, and attend school, without fear of government interference. To protect America from its enemies the executive has begun to stitch shut these security threats. Thus, Americans, their neighbors and visitors, find themselves living out a paradox: in the name of freedom, those seen as suspect - most often visible minorities, non-Christians, the poor and/or unemployed, and dissidents - are continually screened, profiled, and monitored for criminal intent by a web of information-gathering agencies whose inner workings, for security reasons, are not a matter of public record.

The new "high-security" school, in the new "high-security" society sets up, in the public imagination, an ever more dangerous class of youth as perpetual potential wrongdoers. The 
ideology of crime sustained by new school security measures and enhanced reporting systems clearly mirror the Bush administration's proposed Total Information Awareness System (renamed the Terrorist Information Awareness System after congressional and public protest) (McGrath, 2004) and the somewhat more benevolent sounding Canadian version of Homeland Security known as the Emergency Preparedness Program. Two important ideas put forward by Michael Apple in his third edition of Ideology and Curriculum are instructive here. First, in describing what he calls conservative common sense in post 9/11 school policies, he makes clear that common sense is complicated, that it contains both "good sense" and "bad sense" and that, most disturbingly, a form of "conservative modernization" is engaged in a social/pedagogic project to change our common sense (p. 157, emphasis added). Second, he insists that “....any serious understanding of the actual results of September $11^{\text {th }}$ on education needs to widen its gaze beyond what we usually look for" (p. 170). His own examples point to the hidden effects of racism, in particular, in such new norms and unchallenged assumptions.

In that very first discussion that provoked our methodological shift into a drama engagement, among the class of 24 students, there were many who expressed views vehemently opposing the new security measures they have encountered in their school. But there were others who felt they were, indeed, safer because of the new list of "NOs" (no hats on premises; no telephones in schools, including public payphones; no movement in the hallways between periods...) and more rigorous forms of record-keeping and reporting on students' behavior and personal background. Pavlo, a young White boy, said he liked the new record- keeping because that way if anyone was going to get up to no good, the school would be able to anticipate his actions and stop him. To this "common sense" observation, a young Black girl named Trina indignantly replied, "How does knowin' my business make you any safer?" It is, of course, the 
question we must all ask. And it has never been more appropriate than in the post 9/11, postColumbine, post-Taber ${ }^{8}$ world of schools.

\footnotetext{
${ }^{8}$ W. R. Myers High School in Taber, Alberta was the site of a "copy-cat" school shooting a short time after the shooting at Columbine High School in Littleton, Colorado.
} 


\section{References}

Apple, M. W. 2004. Ideology and Curriculum, Third Edition. New York and London: Routledge Falmer.

Best, S. and D. Kellner. 2003. Contemporary Youth and the Postmodern Adventure. The Review of Education, Pedagogy, and Cultural Studies, 25: 75-93.

Besley, A. C. 2003. Hybridized and Globalized: Youth Cultures in the Postmodern Era. The Review of Education, Pedagogy, and Cultural Studies, 25: 153-177.

Britzman, D. 2001. The Arts of Inquiry. Journal of Curriculum Theorizing

Chomsky, N. 2000. Chomsky on Education. Lanham, Boulder, New York, Oxford: Rowman and Littlefield Publishers, Inc.

Eagleton, T. 1996. Literary Theory: An Introduction, $2^{\text {nd }}$ Edition. Oxford: Blackwell Publishing.

Eble, K. 1988. The Craft of Teaching, $2^{\text {nd }}$ Edition. San Francisco: Jossey-Bass.

Felman, J. L. 2001. Never a Dull Moment: Teaching and the Art of Performance. London and New York: Routledge.

Foucault, M. 1990. History of Sexuality: Volume I. New York: Vintage Books.

Freire, P. 1998. On the Relationship Between the Educator and the Learners in Teachers As Cultural Workers: Letters to Those Who Dare Teach. Boulder, Colorado: Westview Press.

Gallagher, K. and C. Fusco. (in press) I.D.ology and the Technologies of Public (School) Space: Who are the Terrorists Among Us? International Journal Of Canadian Studies.

Gallagher, K. 2004. The Art and Politics of Qualitative Research in Drama Education: Creating Culture, Representing 'Reality'. Drama Research. 3:3-18.

Giroux, H. 2003. The A bandoned Generation: Democracy Beyond the Culture of Fear. New York, England: Palgrave Macmillan.

Giroux, H. 1998. Channel Surfing: Racism, The Media, and the Destruction of Today's Youth. New York: St. Martin's Griffin.

Griffiths, M. 1998. Educational Research for Social Justice: getting off the fence. Buckingham and Philadelphia: Open University Press.

Gunier, L and A. Deveare Smith. 2002. "Rethinking Power, Rethinking Theatre" Theatre 31 (3): $31-45$. 
Lesko, N. 2001. Act Your Age: A Cultural Construction of Adolescence. New York and London: Routledge Falmer.

Leistyna, P. 2003. Facing Oppression: Youth Voices from the Front in Education as Enforcement: The Militarization and Corporatization of Schools (K. Saltman and D. Gabbard, eds.). New York and London: RoutledgeFalmer.

Lewis, T. 2003. The Surveillance Economy of Post-Columbine Schools. The Review of Education, Pedagogy, and Cultural Studies, 25: 335-355.

Martusewicz, R. 2001. Seeking Passage: Post-Structuralism, Pedagogy, Ethics. New York: Teachers College Press.

McGrath, J. E. 2004. Loving Big Brother: Performance, Privacy and Surveillance Space. London and New York: Routledge.

McLaren, P. 1986. Schooling As A Ritual Performance. London: Routledge and Keegan Paul.

Peters, M. Cultural studies and the future of 'culture'. New Zealand Sociology. 16:2 (26-47).

Showalter, E. 2003. Teaching Literature. Malden, USA, Oxford, UK, Victoria, Australia, Berlin, Germany: Blackwell Publishing.

Strickland, R. (2002). Growing Up Postmodern: Neoliberalism and the war on the Young. London, Boulder, New York, Oxford: Rowman \& Littlefield Publishers, Inc.

Taft-Kaufman, J. 2004. A TPQ Inteview: Tony Kushner on Theatre, Politics, and Culture. Text and Performance Quarterly. 24(1): 38-54.

Wilshire, B. 1991. Role-Playing and Identity: The Limits of Theatre as Metaphor. Bloomington and Indianapolis: Indiana University Press. 